\title{
Mapping the Influence of Socioeconomic Development Plans on Philippine Health Research Agenda: A Descriptive Study
}

\author{
Jaifred Christian F. Lopez, ${ }^{1}$ Arlene S. Ruiz, ${ }^{2}$ Reneepearl Kim P. Sales, ${ }^{1}$ \\ Maria Angeli C. Magdaraog, ${ }^{1}$ Teddy S. Dizon ${ }^{1}$ and Lester Sam A. Geroy ${ }^{1}$ \\ ${ }^{1}$ Alliance for Improving Health Outcomes, Quezon City, Philippines \\ ${ }^{2}$ National Economic and Development Authority, Pasig City, Philippines
}

\begin{abstract}
Background. Understanding and addressing social determinants of health through evidence-based action is a strategy that has been advocated by the World Health Organization as part of its "Health for All" strategy in 1978 and "Health in All Policies" framework in 2013. It has then been recommended that the research agenda-setting process should be informed by socio-economic development plans with the specific aim of gathering data on social, economic, and cultural conditions that affect health.
\end{abstract}

Objective. This paper reviewed the PDP 2011-2016, PDP 2017-2022, MDGs, and SDGs and identified common directions with the NUHRA 2011-2016 and 2017-2022.

Methods. A content analysis of the three identified priorities of the NUHRA vis-a-vis the PDP 2011-2016, the PDP 2017-2022, the MDGs, and the SDGs was done in order to identify harmonization of the priorities of the NUHRAs targets and indicators with those of the other plans and agendas. A gap analysis across all topics was done to identify links and gaps.

Results. The results established the common ground between health research priorities and international and national plans. Comparing the number of direct relationships between the NUHRAs, PDPs, MDGs, and SDGs, it was noted that there were more direct links between NUHRA 2017-2022, PDP 2017-2022, and the SDGs compared to NUHRA 2011-2016, PDP 2011-2016, and MDGs. The direct links were mostly found in 1) maternal, newborn and child health, 2) health systems, 3) communicable diseases, 4) water, sanitation, and hygiene, 5) environment, and 6) infrastructure development.

Conclusion. The NUHRAs may serve as pathways to achieve the goals stipulated in other socio-economic development plans. The relationships of these to health are complex, nonlinear and often the effects manifest after a long period of time, and as such require rigorous research.

Key Words: National Unified Health Research Agenda, social determinants of health, international and national agendas

\section{INTRODUCTION}

Corresponding author: Jaifred Christian F. Lopez, MD, MPM Alliance for Improving Health Outcomes

62 West Avenue, Quezon City 1104, Philippines

Telephone: +632 2947808

Email: jaifredlopez@gmail.com
Health has been defined not only as the absence of disease or infirmity, but a sense of well-being shaped by socio-economic determinants. These social determinants include working conditions, education, poverty, infrastructure, access to technologies, and culture which influence people's lifestyles and access to health. ${ }^{1}$ Because of this, understanding and addressing social determinants of health (SDH) through evidence-based action is a strategy that has been advocated by the World Health Organization as part of its "Health for All" strategy in 1978 and "Health 
In All Policies" (HIAP) framework in 2013..$^{2-3}$ The "Health For All" slogan encapsulated a call for implementing community-managed health care as facilitated by a new economic international order. ${ }^{3}$ On the other hand, HIAP advocates for the implementation of public policies with consideration of their impact on health outcomes, which inherently requires harmonized intersectoral planning, collaboration, and action. ${ }^{2}$

Research is widely considered as an important component in incorporating $\mathrm{SDH}$ as part of the overall health strategy to reduce inequity. ${ }^{4}$ Despite this, it has been shown globally that $\mathrm{SDH}$ research is funded poorly compared to other fields of health research. ${ }^{5}$ As one of the main drivers of intersectoral engagement for $\mathrm{SDH}$, it has then been recommended that the research agenda-setting process should be informed by socio-economic development plans with the specific aim of gathering data on social, economic, and cultural conditions that affect health. ${ }^{6-8}$ Health research agenda-setting may well be considered an effort in ensuring that health research provides necessary evidence on SDH due to its emphasis on producing research output that is relevant and responsive to population health needs, while also maximizing limited resources. ${ }^{8-10}$

Spearheaded by the Philippine National Health Research System, the Philippines has been on the global front of the health research agenda process due to its early adoption of the Essential National Health Research strategy. ${ }^{9}$ The National Unified Health Research Agenda (NUHRA) enumerates the country's health research priorities generated through multi-stakeholder consultations. Since 2006, the country has produced three NUHRAs: NUHRA 20062010, NUHRA 2011-2016, and NUHRA 2017-2022. Table 1 shows the research areas covered by the NUHRA 2011-2016 and NUHRA 2017-2022..$^{11-12}$

The socio-economic development plans on which the NUHRAs are professedly based include the Philippine Development Plan (PDP), the Millennium Development Goals (MDGs), and the Sustainable Development Goals (SDGs). ${ }^{11-13}$ The PDPs (Table 2) serve as the country's blueprint for socio-economic development and as roadmaps to achieve international goals and targets such as the MDGs and SDGs. It aims to harmonize national programs and

Table 1. NUHRA 2011-2016 and 2017-2022 research priorities

\section{NUHRA 2011-2016}

- Health technology development

o Diagnostics

- Genomics/Molecular technology

o Drug discovery and development

o Functional foods

o Hospital equipment and biomedical devices

o Information Communication Technology for Health

- Health financing

o Financial risk protection

- Health service delivery

o Improving access to quality hospitals and health care facilities

o Improving provision of public health services

- Socio-environmental health concerns

o Environmental and climate change

o Health social sciences

\section{NUHRA 2017-2022}

- Research to enhance and extend healthy

o Adolescent health

- Communicable diseases

o Environmental health

o Maternal, newborn, and child health

- Mental health

o Non-communicable diseases

o Nutrition

o Oral health

- Reproductive health

- Holistic approaches to health and wellness

- Filipino traditional and complementary medicine

o Determinants of health

o Halal in health

o Health behaviors

- Health resiliency

- Accidents and injuries

- Climate change

o Disaster risk reduction and health emergencies

o Emerging and re-emerging diseases

o Environmental threats to health

o Occupational health and migration

- Global competitiveness and innovation in health

o Diagnostics

o Drug discovery and development

Functional foods

Information and communication technologies for health

Biomedical product and engineering

"OMIC" technologies

- Research equity and health

o Disability

o Gender

- Geographically isolated and disadvantaged areas

- Geriatric care

- HIV/AIDS and other STIs

- Indigenous peoples

Substance abuse

Violence

Other vulnerable populations 
Table 2. PDP 2011-2016 and 2017-2022 interventions and pillars

\section{PDP 2011-2016}

1. Macroeconomy

2. Competitive industry and service sectors

3. Competitive and sustainable agriculture and fisheries sectors

4. Accelerating infrastructure development

5. Towards a dynamic and resilient financial system

6. Good governance and the rule of law

7. Social development

8. Peace and security

9. Conservation, protection, and rehabilitation of environment and natural resources

\section{PDP 2017-2022}

1. Pillar 1: Enhancing the social fabric

2. Pillar 2: Inequality-reducing transformation

3. Pillar 3: Increasing growth potential

4. Enabling supportive economic environment

5. Foundations for sustainable development

Table 3. MDGs and SDGs Millennium Development Goals (2000-2015) Sustainable Development Goals (2015-2030)

1. Eradicate extreme poverty and hunger

2. Achieve primary education

3. Promote gender equality and empower women

4. Reduce child mortality

5. Improve maternal health

6. Combat HIV/AIDS, malaria and other diseases

7. Ensure environmental sustainability

8. Global partnership for development

1. No poverty

2. Zero hunger

3. Good health and well-being for people

4. Quality education

5. Gender equality

6. Clean water and sanitation

7. Affordable and clean energy

8. Decent work and economic growth

9. Industry, innovation, and infrastructure

10. Reducing inequalities

11. Sustainable cities and communities

12. Responsible consumption and production

13. Climate action

14. Life below water

15. Life on land

16. Peace, justice, and strong institutions

17. Partnerships for the goals policies, laying out several targets in pursuit of economic growth, employment, human development, equality, and poverty reduction. ${ }^{14-15}$ PDP 2011-2016 emphasized the importance of good governance, ecological integrity and national security that can influence the productive potential of the economy. It pursued five strategies: massive employment, investment in infrastructure, transparent and responsive governance, and develop human resources through improved social services and protection. On the other hand, PDP 2017-2022, is geared towards achieving Ambisyon Natin 2040 which is the collective vision and aspirations of the Filipinos for themselves and for the country. The plan's strategies are clustered into three pillars: malasakit (enhancing the social fabric); pagbabago (inequity-reducing transformation); and patuloy na pagunlad (increasing growth potential). ${ }^{16}$

Furthermore, in 2000, the United Nations promulgated eight MDGs (Table 3) for the international community to achieve by 2015. Of the eight MDGs, four goals have targets directly related to health: 1) reduce child mortality,2) improve maternal health, 3) combat HIV/AIDS, malaria, and other diseases, and 4) ensure environmental sustainability. ${ }^{17}$ The MDGs were used as a framework to guide two NUHRAs: NUHRA 2006-2010 and NUHRA 2011-2016. ${ }^{10,12}$ In 2015, a year after the deadline that was set for achieving the MDGs, the United Nations set 17 new goals and targets to sustain efforts towards global development. The SDGs (Table 3) serve as a policy framework that aims to foster cooperation and collaboration of Member States in common pursuit of inclusive and sustainable development, with an increased focus on human rights. ${ }^{18}$ This set of global commitments was considered in the development of the NUHRA 2017-2022. ${ }^{12}$

Currently, there is a knowledge gap on how health research priorities are influenced by socio-economic development plans. Limited evidence from middle- to highincome countries has shown that socio-economic policies do not often consider health as a factor that could affect the achievement of the main policy outcomes. ${ }^{19}$ Effects of contractionary and expansionary fiscal policies on health vary across countries and largely depend on the circumstances under which they were implemented, ${ }^{20}$ which may affect likewise how limited resources are prioritized, ultimately influencing the choice of research priorities to be funded by government. In view of these considerations, this paper reviews the socio-economic plans and identified common directions with the NUHRA from 2011 to 2022, while being guided with the underlying assumption that if health research agenda would be influenced by socio-economic policy, it can garner broad-based support. Specifically, this paper examines the extent to which the NUHRAs were anchored to these goals through a qualitative thematic analysis approach. 


\section{MATERIALS AND METHODS}

This qualitative study implemented a cross-sectional thematic analysis of the health research priorities, areas, and topics of NUHRA 2011-2016 and 2017-2022 with the interventions and pillars of PDP 2011-2016 and PDP 2017-2022, and international targets of the MDGs, and SDGs. Consistent with the thematic analysis methodology described by Nowell and colleagues, ${ }^{21}$ these documents were thoroughly familiarized, initial codes were generated, and themes were searched, reviewed, defined and named. Themes that emerged from the analysis of the NUHRA documents were then matched with targets and goals included in the PDPs, MDGs, and SDGs that corresponded with the years of coverage (e.g. NUHRA 2011-2016 was analyzed alongside PDP 2011-2016 and the MDGs). Due to the lack of correspondence with the year of coverage of its counterpart PDP, the NUHRA 2006-2010 was excluded from the analysis. The NUHRA themes and the goals and targets of the PDPs, MDGs and SDGs were qualitatively categorized as a "direct" relationship, which indicated that a research priority can be directly linked with the target of PDPs, MDGs, or SDGs.

Aside from the exclusion of NUHRA 2006-2010 in the analysis, other important limitations of this study are 1) that the status of progress and outputs for the various goals and priorities was not assessed and 2) general topic headings were used to depict the alignment of targets with included priorities, due to the large number of subtopics.

\section{RESULTS}

\section{NUHRA 2011-2016 and PDP 2011-2016}

Analyzed alongside the PDP 2011-2016 interventions, the health financing, health service delivery, and socioenvironmental health concern priorities of the NUHRA 2011-2016 can be directly linked with four out of nine PDP 2011-2016 interventions (Table 4): 1) social development, 2) good governance and the rule of law, 3) conservation, protection, and rehabilitation of environment and natural resources, and 4) accelerating infrastructure development.

Table 4. NUHRA 2011-2016 and PDP 2011-2016

\begin{tabular}{|c|c|c|}
\hline \multicolumn{2}{|c|}{ NUHRA 2011-2016 } & \multirow{2}{*}{ PDP 2011-2016 } \\
\hline Research priorities & Research area & \\
\hline Health financing & $\begin{array}{l}\text { Financial risk } \\
\text { protection }\end{array}$ & Social development \\
\hline $\begin{array}{l}\text { Health service } \\
\text { delivery }\end{array}$ & $\begin{array}{l}\text { Improving access to } \\
\text { quality hospitals and } \\
\text { health care facilities }\end{array}$ & $\begin{array}{l}\text { Good governance } \\
\text { and the rule of law }\end{array}$ \\
\hline \multirow[t]{2}{*}{$\begin{array}{l}\text { Socio-environmental } \\
\text { health concerns }\end{array}$} & \multirow[t]{2}{*}{$\begin{array}{l}\text { Environmental and } \\
\text { climate change }\end{array}$} & $\begin{array}{l}\text { Conservation, } \\
\text { protection, and } \\
\text { rehabilitation of } \\
\text { environment and } \\
\text { natural resources }\end{array}$ \\
\hline & & $\begin{array}{l}\text { Accelerating } \\
\text { infrastructure } \\
\text { development }\end{array}$ \\
\hline
\end{tabular}

In PDP 2011-2016, one of the major outcomes under social development is improved health and nutrition status. Recommended strategies to achieve this include providing universal health care to all and expanding social protection programs for priority beneficiaries including vulnerable groups. This directly links with the health financing research priority of NUHRA 2011-2016, which aimed to increase PhilHealth enrollment coverage, improve benefits availment, and increase support for the National Health Insurance Program to provide Filipinos substantial financial risk protection. It also links with the health service delivery research priority, which aimed to improve access to quality hospitals and health facilities through the upgrading and expanding of their capacities, as shown in Table 4.

Strategies and interventions under good governance and rule of law aimed to set normative standards of development through fostering participation, accountability, transparency, efficiency, and upholding of the rule of law. This is directly linked with one of the topics under the health service delivery research priority: determine voice of customer. This research topic was concerned with the determining the actual health needs of patients with chronic illnesses and patient at risk of nutritional deficiencies.

The strategies on conservation, protection and rehabilitation of the environment and natural resources envisioned a healthy, productive, resilient and sustainable environment for the future generation of the Filipinos. This is in direct link with the health research priority on environmental and climate change, which included specific research topics on the development of costeffective technologies to prevent, control, and monitor environmental pollution.

Accelerating infrastructure development was pursued to ensure equitable access to services that affects people's health, education, and housing. This is also directly linked with the research priority on environmental and climate change, which included a specific research topic on reduction of water and sanitation related diseases.

\section{NUHRA 2011-2016 and MDGs}

The health technology development, health service delivery, and socio-environmental health concern priorities of the NUHRA 2011-2016 can be directly linked with four out of the eight MDGs (Table 5): 1) combat HIV/AIDS, malaria, and other diseases, 2) reduce child mortality, 3) improve maternal health, and 4) ensure environmental sustainability.

The goal to combat HIV/AIDS, malaria, and other diseases had three targets:

1. halt and begin to reverse the spread of HIV/AIDS,

2. achieve universal access to treatment for HIV/ AIDS, and

3. halt and begin to reverse the incidence of malaria and other major diseases. ${ }^{17}$

This is directly linked with the research priorities of health technology development and socio-environmental 
Table 5. NUHRA 2011-2016 and MDGs

\begin{tabular}{|c|c|c|c|}
\hline \multicolumn{2}{|c|}{ NUHRA 2011-2016 } & \multirow{2}{*}{\multicolumn{2}{|c|}{ MDGs }} \\
\hline Research priority & Research area & & \\
\hline $\begin{array}{l}\text { Health technology } \\
\text { development }\end{array}$ & Diagnostics & \multicolumn{2}{|c|}{$\begin{array}{l}\text { Combat HIV/AIDS, } \\
\text { malaria, and other diseases }\end{array}$} \\
\hline $\begin{array}{l}\text { Health service } \\
\text { delivery }\end{array}$ & $\begin{array}{l}\text { Improving access } \\
\text { to quality hospitals } \\
\text { and health care } \\
\text { facilities }\end{array}$ & \multirow{2}{*}{$\begin{array}{l}\text { Reduce } \\
\text { child } \\
\text { mortality }\end{array}$} & $\begin{array}{l}\text { Improve } \\
\text { maternal } \\
\text { health }\end{array}$ \\
\hline \multirow{2}{*}{$\begin{array}{l}\text { Socio- } \\
\text { environmental } \\
\text { health concerns }\end{array}$} & $\begin{array}{l}\text { Health social } \\
\text { sciences }\end{array}$ & & $\begin{array}{l}\text { Combat HIV/ } \\
\text { AIDS, malaria, } \\
\text { and other } \\
\text { diseases }\end{array}$ \\
\hline & $\begin{array}{l}\text { Environmental and } \\
\text { climate change }\end{array}$ & \multicolumn{2}{|c|}{$\begin{array}{l}\text { Combat HIV/AIDS, } \\
\text { malaria, and other } \\
\text { diseases } \\
\text { Ensure environmental } \\
\text { sustainability }\end{array}$} \\
\hline
\end{tabular}

health concerns, which included subtopics on development of diagnostic kits for priority diseases and the development of health social science approach and integrated intervention models to reduce prevalence of infectious diseases, including those attributed to environmental changes.

The goal of reducing child mortality aimed to reduce the mortality rate of children under five by two-thirds while improving maternal health targeted a reduction of maternal mortality ratio by three-quarters. ${ }^{17}$ This is directly linked with the health service delivery and socio-environmental concerns research priorities. These research priorities included subtopics on review of the Basic Emergency Obstetric and Newborn Care (BEmONC) and Comprehensive Emergency Obstetric and Newborn Care (CEmONC) system and the development of a health social science approach to address issues in childhood illnesses.
The goal of ensuring environmental sustainability included targets such as:

1. halving the proportion of the population without sustainable access to safe drinking water and basic sanitation,

2. achieving a significant improvement in the lives of at least 100 million slum dwellers [globally], and

3. integrating principles of sustainable development into country policies and programs. ${ }^{17}$

This is in line with the research priority of socioenvironmental health concerns, which had subtopics on reducing prevalence of water- and sanitation-related diseases and developing health technologies to prevent, monitor, and control environmental pollution.

\section{NUHRA 2017-2022 and PDP 2017-2022}

The health technology development, responsive health systems, research to enhance and extend healthy lives, health resiliency, and research in equity and health priorities of the NUHRA can be directly linked with the three major pillars and strategies of the PDP 2017-2022 (Table 6): 1) enhancing the social fabric, 2) inequality reducing transformation, and 3 ) increasing growth potential. It can also be linked with the foundations of sustainable development strategy that supports these pillars.

The inequality-reducing transformation pillar aims to bring about change through the inclusion of strategies such as acceleration of human capital development and reduction of vulnerability of individuals and families. This is in line with the priorities on responsive health systems, research to enhance and extend healthy lives, health resiliency, and research in equity and health. These research priorities include studies on 1) increasing financial risk protection of

Table 6. NUHRA 2017-2022 and PDP 2017-2022

\begin{tabular}{|c|c|c|c|}
\hline \multicolumn{2}{|c|}{ NUHRA 2017-2022 } & \multirow{2}{*}{\multicolumn{2}{|c|}{ PDP 2017-2022 }} \\
\hline Research priority & Research area & & \\
\hline \multirow{4}{*}{ Responsive health systems } & Health governance & \multicolumn{2}{|c|}{ Enhancing the social fabric } \\
\hline & Health financing & \multirow{16}{*}{ Inequality-reducing } & \multirow{7}{*}{$\begin{array}{l}\text { Increasing growth } \\
\text { potential }\end{array}$} \\
\hline & Health economics & & \\
\hline & Health service delivery & & \\
\hline \multirow{7}{*}{$\begin{array}{l}\text { Research to enhance and } \\
\text { extend healthy lives }\end{array}$} & Adolescent health & & \\
\hline & Reproductive health & & \\
\hline & Maternal, newborn, and child health & & \\
\hline & Nutrition & & \\
\hline & Communicable diseases & & \\
\hline & Non-communicable diseases & & \\
\hline & Environmental health & & \multirow{7}{*}{$\begin{array}{l}\text { Foundations } \\
\text { for sustainable } \\
\text { development }\end{array}$} \\
\hline \multirow{4}{*}{ Health resiliency } & Accidents and injuries & & \\
\hline & Emerging and re-emerging diseases & & \\
\hline & Disaster risk reduction and health emergencies & & \\
\hline & Environmental threats to health & & \\
\hline \multirow{2}{*}{ Research in equity and health } & HIV/AIDS and other STIs & & \\
\hline & Substance abuse & & \\
\hline
\end{tabular}


patients, 2) improving accessibility, effectivity, and efficiency, of health services, 3) key health issues on adolescent, reproductive, nutritional, and maternal, newborn, and child health, 4) communicable diseases, non-communicable diseases, 5) substance abuse, and 6) disaster risk reduction and health emergencies.

The foundations for sustainable development strategy are characterized by infrastructure development that ensures ecological integrity and a clean and healthy environment. This is directly linked with the research to enhance and extend healthy lives and health resiliency, which includes research on the effects of poor environmental health conditions on health and public health solutions for road safety and injury prevention.

The increasing growth potential pillar is concerned with the demographic transitional needs that will enable the economy to reap the demographic dividend. The strategy is characterized by shifting and accelerating the demography of the country into the low mortality and fertility levels that facilitate the shift so that the working age comprises the bulk of the population - also called the demographic window of opportunity. This is directly linked with the research to enhance and extend healthy lives, which includes studies on teenage pregnancy, family planning, and improvement of maternal, newborn, and child health and nutrition services and programs.

The enhancing the social fabric pillar aims to regain people's trust by making public institutions citizen-centered, efficient and clean. This is directly linked with the responsive health systems research priority, which includes research on evidence-based policy formulation, health governance in leadership, enforcement, and regulation at all levels.

\section{NUHRA 2017-2022 and SDGs}

All research priorities of the NUHRA 2017-2022 except global competitiveness and innovation in health can be directly linked with 10 out of 17 SDGs (Table 7): 1) no poverty, 2) good health and well-being for people,

Table 7. NUHRA 2017-2022 and SDGs

\begin{tabular}{|c|c|c|c|c|c|}
\hline \multicolumn{2}{|c|}{ NUHRA 2017-2022 } & \multirow{2}{*}{\multicolumn{4}{|c|}{ SDGs }} \\
\hline \multicolumn{2}{|l|}{ Research priority } & & & & \\
\hline \multirow{6}{*}{ Responsive health systems } & Health governance & \multicolumn{4}{|c|}{ SDG 16: Peace, justice, and strong institutions } \\
\hline & Health research management & & & & \\
\hline & Health financing & \multirow{11}{*}{$\begin{array}{l}\text { SDG 3: Good } \\
\text { health and } \\
\text { well-being } \\
\text { for people }\end{array}$} & \multirow{4}{*}{\multicolumn{3}{|c|}{ SDG 10: Reducing inequalities }} \\
\hline & $\begin{array}{l}\text { Access to essential medical products, } \\
\text { vaccines, and technologies }\end{array}$ & & & & \\
\hline & \begin{tabular}{|l|} 
Health economics \\
\end{tabular} & & & & \\
\hline & Health service delivery & & & & \\
\hline \multirow{7}{*}{$\begin{array}{l}\text { Research to enhance and } \\
\text { extend healthy lives }\end{array}$} & Adolescent health & & \multirow{4}{*}{\multicolumn{2}{|c|}{ SDG 1: No poverty }} & \multirow{3}{*}{$\begin{array}{l}\text { SDG 5: Gender } \\
\text { equality }\end{array}$} \\
\hline & Reproductive health & & & & \\
\hline & Maternal, newborn, and child health & & & & \\
\hline & Environmental health & & & & $\begin{array}{l}\text { SDG 6: Clean water } \\
\text { and sanitation }\end{array}$ \\
\hline & Nutrition & & & & \\
\hline & Communicable diseases & & & & \\
\hline & Non-communicable diseases & & & & \\
\hline $\begin{array}{l}\text { Holistic approaches to } \\
\text { health and wellness }\end{array}$ & Health behaviors & \multirow{2}{*}{\multicolumn{3}{|c|}{ SDG 1: No poverty }} & \\
\hline \multirow{6}{*}{ Health resiliency } & $\begin{array}{l}\text { Disaster risk reduction and } \\
\text { health emergencies }\end{array}$ & & & & $\begin{array}{l}\text { - SDG 11: } \\
\text { Sustainable cities } \\
\text { and communities } \\
\text { - SDG 13: Climate } \\
\text { action }\end{array}$ \\
\hline & Emerging and re-emerging diseases & \multirow{3}{*}{\multicolumn{3}{|c|}{$\begin{array}{l}\text { SDG 3: Good health and } \\
\text { well-being for people }\end{array}$}} & \\
\hline & Environmental threats to health & & & & $\begin{array}{l}\text { SDG 12: Responsible } \\
\text { consumption and } \\
\text { production }\end{array}$ \\
\hline & Accidents and injuries & & & & \\
\hline & Climate change & \multicolumn{4}{|c|}{ SDG 13: Climate action } \\
\hline & Occupational health and migration & \multicolumn{4}{|c|}{ SDG 8: Decent work and economic growth } \\
\hline \multirow{4}{*}{ Research in equity and health } & HIV/AIDS and other STIs & \multirow{2}{*}{\multicolumn{4}{|c|}{ SDG 3: Good health and well-being for people }} \\
\hline & Substance abuse & & & & \\
\hline & Gender & \multirow{2}{*}{\multicolumn{2}{|c|}{ SDG 5: Gender equality }} & & \\
\hline & Violence & & & $\begin{array}{l}\text { SDG } \\
\text { and s }\end{array}$ & $\begin{array}{l}\text { 6: Peace, justice, } \\
\text { ong institutions }\end{array}$ \\
\hline
\end{tabular}


3) gender equality, 4) clean water and sanitation, 5) decent work and economic growth, 6) reducing inequalities, 7) sustainable cities and communities, 8) responsible consumption and production, 9) climate action, and 10) peace, justice, and strong institutions.

Good health and well-being for people is concerned with improving indicators for maternal, newborn, and child health and communicable diseases such as HIV/AIDs, malaria, and tuberculosis through universal health coverage and access to safe and affordable medicines and vaccines for all. This corresponds with the research priorities on research in equity and health, health resiliency, research to enhance and extend healthy lives, and responsive health systems. These research priorities include research areas such as health service delivery, communicable diseases, HIV/AIDS, emerging and re-emerging diseases, adolescent health, and maternal, newborn, and child health.

To efficiently reduce inequities, sound policies should be adopted to empower the low-income earners and promote economic inclusion, ensure fiscal protection, and equal opportunity for all regardless of sex, disability, religion, or economic status. This is directly linked with the responsive health systems research priority, which includes studies on financing mechanisms, allocation and distribution of medicines, available health services, and efficient health interventions.

Eradicating all poverty involves targeting the most vulnerable, increasing access to basic resources and services, as well as supporting communities affected by conflict and climate-related disasters. This corresponds with research under research to enhance and extend healthy lives, health resiliency, and holistic approaches to health and wellness, which includes studies on adolescent, maternal, newborn, and child and reproductive health services, health behaviors, and disaster risk reduction.

Gender equality aims to end all forms of discrimination against women and girls though equal rights to land and property and ensuring universal access to sexual and reproductive health. This is in direct link with the priorities of research to enhance and extend healthy lives and research in equity and health. These priorities include studies on adolescent, maternal, newborn, and child and reproductive health, and gender and violence.

The peace, justice and strong institutions SDG aims to reduce all forms of violence, promote justice for all, and build accountable and inclusive institutions. This directly corresponds with the responsive health systems and research in equity and health priorities, which includes topics on health governance and populations subject to violence.

Climate action is concerned with climate change adaptation through efforts to integrate disaster risk measures into national strategies. Creating sustainable cities and communities ensures access to safe housing and upgrading slum settlements. Responsible production and consumption require efficient management of resources and disposal of toxic wastes and pollutants. These three SDGs align with the health resiliency research priority, which includes research that address the health effects of pollutants and health emergency interventions, infrastructure, and capacity.

Finally, access to clean water and sanitation requires investment in infrastructure and hygiene encouragement at every level. This directly aligns with the research to enhance and extend healthy lives research priority, which includes studies on water quality and management, and sanitation and hygiene.

\section{DISCUSSION}

The results established the common ground between health research priorities and international and national plans. Weighing the number of direct relationships between the NUHRAs, PDPs, MDGs, and SDGs, it was noted that there were more direct links between NUHRA 2017-2022, PDP 2017-2022, and the SDGs compared to NUHRA 2011-2016, PDP 2011-2016, and MDGs. The direct links were mostly found in 1) maternal, newborn and child health, 2) health systems, 3) communicable diseases, 4) water, sanitation, and hygiene, 5) environment, and 6) infrastructure development. These topics have prevailed throughout the NUHRAs, which indicate that these issues continue to persist in the country. Meanwhile, the health research agenda documents analyzed did not include topics typical of the industry and service sectors, macroeconomic policies, agriculture, and fisheries, although it may be noted that these sectors have their own respective research agenda in other fields of study.

It is important to recognize the complex relationship of health to other sectors. Framing health research to consider these complexities sheds light on the direct links of health to other socio-economic factors. Health research focus on social determinants of health is also important to provide long term solutions to long-standing societal problems. ${ }^{22}$ Some countries have steered their health research agendas to address factors beyond the control of the health system. The United Kingdom's Department of Health and Social Care launched a strategy to promote national economic growth by harnessing biomedical research to meet the needs of industry and enhance research productivity through market competition. ${ }^{23}$ In Iran, all provincial Councils of Health and Food Security are mandated to create a Health Master Plan to operationalize the Health in All Policies approach. ${ }^{24}$ The results show that the country's health research priorities can go beyond the focus of health outcomes and contribute to other goal areas of international and national socioeconomic development plans.

Research priority-setting is a crucial step in allocating resources in a manner that appropriately considers the political and socio-economic conditions. The gaps and links in certain areas may reveal political commitments and national ambitions. ${ }^{25}$ Tying in directions from international 
and national plans increases the support and uptake of the various NUHRA research areas by various agencies and institutions. ${ }^{26}$ In the case of the NUHRA 2011-2016 and 2017-2022, this was considered through the employment of a top-down approach, where input from various institutions were considered. However, organizational and institutional support should be counterbalanced by the emergent needs of the country. In regarding global ambitions and commitments for health research agendas, tailoring global initiatives to national context is crucial. ${ }^{27}$ The bottom-up approach employed in NUHRA 2017-2022 allowed integration and harmonization of plans whilst also contextualizing and prioritizing points in agendas through evidence.

Despite achievement of harmonization, the persistent inclusion of research priorities through different timeframes may indicate challenges in translating research into action. ${ }^{28}$ It has been shown that the most important facilitator of research translation into action is the contact and relationship between policy-makers and researchers. ${ }^{29}$ Thus, to incorporate social determinants of health into multisectoral policies, the HIAP framework recommends six components that are crucial to put the approach into action. ${ }^{2}$ First, establishment of the need and priorities for HIAP may be needed to strategically plan, assess health implications of policies, understand context, and map regulatory oversight and implementation capacity. Second, a frame planned action is necessary so that feasible implementation strategies may be utilized. Third, relevant actors within and beyond the health sector may need to be identified and health implications must be promoted at every level. Next, health impact of policies should be assessed, and key stakeholders and communities impacted by these policies should be engaged. Fifth, the continuous approach must be monitored and evaluated properly, with collaboration point and specific focus areas identified early. Finally, promotion and implementation of HIAP requires new knowledge and skills that may be acquired through training or knowledge dissemination.

\section{CONCLUSION AND RECOMMENDATIONS}

The results from this study helped established a common ground for health and social development, as well as the existence of gaps that could be further explored. As part of the social determinants of health, these links should be emphasized and strengthened in order to deliver a multisectoral approach to health. As such, a full picture of the mechanisms of social determinants of health cannot be achieved by the conducted analysis. The relationships of socio-economic factors to health are complex, nonlinear, and often manifest after a long period of time.

There are other unrecognized and unmeasured social determinants of health that are not included in international and national socio-economic plans and the health agenda. The NUHRA priorities are mainly focused on addressing health outcomes. However, there is space to explore the social determinants of health, particularly in the gap areas seen in the results of this study.

In the priority setting process, the multisectoral nature of this approach might find challenges in carrying out coherence and harmony of goals and objectives when faced with stakeholders with differing priorities. The NUHRAs may serve as pathways to achieve the goals stipulated in other socio-economic plans but the current targets can still be expanded to pursue more holistic and distinct agenda priorities.

More insights could be gained if empirical evidence can be gathered on the status and improvements in the various goal areas throughout the three NUHRAs, such as those that can be gathered from focus group discussions with stakeholders, and analysis of workshop reports. Further studies on this could reveal if the same problems been persistent for the past years and evaluate the outputs and outcomes of the NUHRAs. It is necessary to assess the status in these areas to track the progress and further inform researchers and decisionmakers to improve health and create holistic and harmonized health research and socio-economic development agendas.

\section{Acknowledgments}

The authors would like to gratefully acknowledge the contributions of Prof. Marilyn Ellorin-Crisostomo, Dr. Katherine Villegas-Reyes, Dr. James Salisi, Dr. Joseph Oraño, and Ms. Camille Rivera; and the helpful comments of the peer reviewers.

\section{Statement of Authorship}

All authors approved the final version submitted.

\section{Author Disclosure}

All authors declared no conflict of interest.

\section{Funding Source}

This paper was funded by the Philippine Council for Health Research and Development.

\section{REFERENCES}

1. Braveman P, Egerter S, Williams DR. The social determinants of health: coming of age. Annu Rev Public Health 2011; 32:381-98. doi: 10.1146/annurev-publhealth-031210-101218.

2. World Health Organization. Health in all policies (HIAP) framework for country action [Internet]. 2014 Jan [cited 2018 Aug 20]. Available from: https://www.who.int/cardiovascular_ diseases/140120HPRHiAPFramework.pdf.

3. Mahler H. The Meaning of "Health for All by the Year 2000". Am J Public Health. 2016;106(1):36-8.

4. Social Determinants of Health Network [Internet]. SDH-Net: SDHNet. 2011 [cited 2018 Aug 20]. Available from: http://www.sdh-net. eu/project/the-project/.

5. Guglielmin M, Muntaner C, O'Campo P, Shankardass K. A scoping review of the implementation of health in all policies at the local level. Health Policy. 2018 Mar; 122(3):284-92. doi: 10.1016/j. healthpol.2017.12.005. 
6. Woolf SH, Purnell JQ, Simon SM, Zimmerman EB, Camberos GJ, Haley A, et al. Translating evidence into population health improvements: strategies and barriers. Annu Rev Public Health. 2015 Mar 18; 36:463-82. doi: 10.1146/annurev-publhealth-082214-110901.

7. Borrell C, Malmusi D. Research on social determinants of health and health inequalities: evidence for health in all policies. Gac Sanit. 2010 Dec; 24 Suppl 1:101-8. doi: 10.1016/j.gaceta.2010.05.005. (Spanish).

8. Freiler A, Muntaner C, Shankardass K, Mah C, Molnar A, Renahy E, et al. Glossary for the implementation of Health in All Policies (HiAP). J Epidemiol Community Health. 2013 Dec 1; 67(12):1068-72.

9. Council for Health Research and Development (COHRED). Essential National Health Research and Priority Setting: Lessons Learned [Internet]. 1997 [cited 2018 Aug 20]. Available from: http:// www.cohred.org/downloads/586.pdf.

10. Viergever RF, Olifson S, Ghaffar A, Terry RF. A checklist for health research priority setting: nine common themes of good practice. Health Res Policy Syst. 2010 Dec 15; 8:36. doi: 10.1186/1478-4505-8-36.

11. Philippine National Health Research System. National Unified Health Research Agenda 2011-2016. 2011.

12. Philippine National Health Research System. National Unified Health Research Agenda 2017-2022. 2017.

13. Philippine National Health Research System. National Unified Health Research Agenda 2006-2010. 2006.

14. National Economic Development Authority. Philippine Development Plan 2011-2016. Manila, Philippines: NEDA; 2011.

15. National Economic Development Authority. Philippine Development Plan 2017-2022. Manila, Philippines: NEDA; 2017.

16. National Economic Development Authority. Ambisyon Natin 2040: A Long-term Vision for the Philippines [Internet]. Manila: NEDA; 2016 [cited 2018 Aug 21]. Available from: http://2040.neda.gov. $\mathrm{ph} / \mathrm{wp}$-content/uploads/2016/04/A-Long-Term-Vision-for-thePhilippines.pdf/.

17. United Nations. United Nations Millenium Development Goals [Internet]. UN; 2000 [cited 2018 May 2]. Available from: http://www. un.org/millenniumgoals/.

18. United Nations. Sustainable Development Goals [Internet]. UN; 2015 [cited 2018 May 2]. Available from: https://www.un.org/ sustainabledevelopment/sustainable-development-goals/.

19. Osypuk TL, Joshi P, Geronimo K, Acevedo-Garcia D. Do Social and Economic Policies Influence Health? A Review. Curr Epidemiol Rep. 2014 Sep 1; 1(3):149-64.
20. Mosquera I, Gonzales-Rabago Y, Bacigalupe A, Suhrcke M. The impact of fiscal policies on socioeconomic determinants of health: a structured review. Int J Health Serv. 2017 Apr; 47(2):189-206. doi: 10.1177/0020731416681230.

21. Nowell L, Norris J, White D, Moules N. Thematic analysis: striving to meet the trustworthiness criteria. Int J Qual Methods. 2017; 16:1-13. doi: $10.1177 / 1609406917733847$.

22. University of Kansas Center for Community Health and Development [Internet]. Social Determinants of Health Kansas: University of Kansas; 2018 [cited 2018 May 2]. Available from: https://ctb.ku.edu/ en/table-of-contents/analyze/analyze-community-problems-andsolutions/social-determinants-of-health/main.

23. Pollock A, McNally N, Kerrison S. Best research: the new UK medical research strategy helps industry but will it improve health? BMJ. 2006 Feb 4; 332(7536):247-8. doi: 10.1136/bmj.332.7536.247.

24. Khayatzadeh-Mahani A, Sedoghi Z, Mehrolhassani M, YazdiFeyzabadi V. How Health in All Policies are developed and implemented in a developing country? A case study of a HiAP initiative in Iran. Health Promot Int. 2016 Dec; 31(4):769-81.

25. Ali N, Hill C, Kennedy A, IJsselmuiden C. What factors influence national health research agenda in low and middle income countries? [Internet]. 2006 [cited 2018 Aug 20]. Available from: http://www. cohred.org/downloads/cohred_publications/rp5.pdf.

26. Montorzi G, de Haan S, IJsselmuiden C. Council on Health Research for Development. COHRED, Priority Setting for Research for Health: a management process for countries [Internet]. 2010 Aug [cited 2018 Aug 20]. Available from: http://www.cohred.org/downloads/Priority_ Setting_COHRED_approach_August_2010.pdf.

27. Prinja S. Role of ideas and ideologies in evidence-based health policy. Iran J Public Health. 2010; 39(1):64-9.

28. Chalmers I, Bracken MB, Djubelgovic B, Garattini S, Grant J, Gulmezoglu AM, et al. How to increase value and reduce waste when research priorities are set. Lancet. 2014 Jan 11; 383(9912):156-65. doi: 10.1016/S0140-6736(13)62229-1.

29. Oliver K, Lorenc T, Innvaer S. New directions in evidence-based policy research: a critical analysis of the literature. Health Res Policy Syst. 2014 Jul 14; 12(34). doi: 10.1186/1478-4505-12-34. 